\title{
The Emerging Role of IL-I7 in the Immune-Pathogenesis of Chronic Spontaneous Urticaria
}

This article was published in the following Dove Press journal: ImmunoTargets and Therapy

\author{
Elias Toubi ${ }^{1}$ \\ Zahava Vadasz ${ }^{2}$ \\ 'The Outpatient Allergy Clinic, The Holy \\ Family Hospital, Nazareth, Israel; ${ }^{2}$ The \\ Proteomic Unit, The Division of Clinical \\ Immunology, Bnai-Zion Medical Center, \\ Faculty of Medicine, Technion, Haifa, \\ Israel
}

\begin{abstract}
Chronic spontaneous urticaria (CSU) is considered to be an autoimmune disorder (type I and type II) in 50\% of all cases. However, autoreactive T cells and their proximity with activated mast cells in the skin of CSU patients are believed to be the primary event in mast cell degranulation. The finding of anti-FceRI $\alpha$ on mast cells or IgE autoantibodies against thyroid antigens should be considered to be a consequence of the auto-reactive $\mathrm{T}$ cells' recognition of the above-mentioned antigens. Our recent finding of increased Th17 and IL-17 expression in both CD4+ T cells and mast cells in the skin of severe CSU patients is supportive for the major role that $\mathrm{T}$ cells perform in the pathogenesis of CSU. Supporting this are numerous previous reports in which increased serum IL-17 was found to be in association with CSU disease severity. The beneficial effect of anti-IL-17A (secukinumab) in CSU patients in whom high dose anti-histamines, recurrent course of steroids and omalizumab fail to achieve a reasonable response should be investigated as a new therapeutic strategy in future studies with a large cohort of patients.
\end{abstract}

Keywords: IL-17, interleukin-17, chronic spontaneous urticaria, CSU, T cells, mast cells

\section{Introduction}

Chronic spontaneous urticaria (CSU) is a common skin disorder, characterized by recurrent episodes of mast cell-driven transient itchy hives, which are often associated with attacks of angioedema. The clue to being an autoimmune disorder in origin (at least in part) had already been reported four decades ago. This was reflected by the finding of anti-thyroid antibodies and other antinuclear antibodies in $15-20 \%$ of CSU patients. ${ }^{1}$ Antinuclear antibodies are continuously reported to be common in CSU patients and also linked to their poor response to omalizumab treatment. $^{2}$ Thyroid autoimmunity in euthyroid patients was reported to be associated with chronic urticaria and the treatment with thyroxin resulted in clinical remission in few of them. ${ }^{3}$ The report of a positive autologous serum skin test (ASST) in half of CSU patients supported the concept that autoimmunity could be involved in the pathogenesis of CSU. A marked neutrophil infiltrate was seen both within and around small dermal blood vessels at the autologous serum injection site in association with the urticaria activity score. ${ }^{4}$ In another study, anti-thyroid antibody titer and B-cell percentage were found to be higher in patients with a positive ASST than in those with negative results. ${ }^{5}$ Subsequently, autoimmunity was further established when histamine-releasing IgG autoantibodies against the alpha subunit
Correspondence: Zahava Vadasz Email zahava.vadas@b-zion.org.il
ImmunoTargets and Therapy 2020:9 217-223 
of the high-affinity $\operatorname{IgE}$ receptors (FceRI $\alpha$ ) or $\operatorname{IgE}$ on mast cells were described. IgG autoantibodies induced the cross-linking of $\mathrm{IgE}$ receptors on mast cells, thereby inducing their degranulation and histamine release. ${ }^{6}$ This was later classified to be type II autoimmunity in CSU. In contrast to this, type I autoimmunity in CSU was characterized by the finding of IgE autoantibodies against thyroid antigens such as thyroid peroxidase (TPO) and/or autoallergens. Passive transfer of anti-TPO IgE from CSU patient to the skin of control subjects without anti-TPO IgE induced a positive skin reaction. This suggests that IgE against TPO plays a pathogenic role in inducing effector cell activation and skin exacerbation in some patients with $\mathrm{CSU}^{7}$ Autoimmunity, of any type, is considered to be found in up to $50 \%$ of all CSU cases. ${ }^{8,9}$ The role of $\mathrm{T}$ cells, namely auto-reactive $\mathrm{T}$ cells in the autoimmune scenario of CSU was also reported four decades ago. This was evident by the discovery of increased infiltration of CD4+ T helper cells in the skin of CSU, most of which co-expressed HLA-DR antigen. ${ }^{10}$ Uncontrolled T-cell activation was further reported to be in peripheral blood as well as in lesional and non-lesional skin of CSU patients. In this context, $47 \%$ of the perivascular cellular infiltrate were found to be $\mathrm{T}$ lymphocytes and $22 \%$ were monocytes, suggesting that $\mathrm{T}$ cells are front players in the pathogenesis of CSU. ${ }^{11}$ In light of the abundant evidences that chronic urticaria is an autoimmune disease, cellular markers of autoimmunity on $\mathrm{T}$ lymphocytes were assessed. CD40Ligand (CD40L) expression was found to be significantly higher on activated T-cells from chronic urticaria patients compared with that of contact dermatitis and healthy individuals. Higher bcl-2 expression in T cells of severe chronic urticaria patients was also documented as compared with the control groups. These findings were similar to those found in T cells of SLE patients, providing an evidence that chronic urticaria could be an autoimmune disease. ${ }^{12}$ In this respect, cyclosporine A (a drug that inhibits T-cell proliferation, induces apoptosis of CD4+ $\mathrm{T}$ cells and down-regulates T-cell mediated proinflammatory cytokines) was proven to be highly beneficial in the treatment of severe CSU, supporting the concept that un-controlled $\mathrm{T}$ cells are indeed important in the pathogenesis of CSU. ${ }^{13}$ Blood autoreactive CD4+ T cell proliferation to FceRIa was detected in $27 \%$ of $\mathrm{CSU}$ patients but not in any of the healthy individuals. IFN- $\gamma$ responses to FceRI $\alpha$ were detected in $53 \%$ of patients, and serum FceRI $\alpha$ autoantibodies were detected in $43 \%$ of $\mathrm{CSU}$ subjects. IFN- $\gamma$ and autoantibody responses to
FceRIa were inversely related. Autoreactive T-cell responses (IFN- $\gamma$ responses) were detected earlier than autoantibodies, suggesting that both findings represent different stages in CSU course. ${ }^{14}$ This information supports the notion that CSU is indeed a T-cell mediated, rather than a humoral-mediated immune disorder, and that type I and type II autoimmunity may develop as a consequence of un-controlled activity of auto-reactive T-cells. Depending on the cytokine milieu in CSU, CD4+T cells can differentiate into pro-inflammatory T helper 1 (Th1), anti-inflammatory Th2, pro-inflammatory Th17 and T regulatory (Treg) cells. Following the discovery of interleukin (IL)-17 producing $\mathrm{T}$ helper (Th17) cells as a distinct lineage derivation of CD4 $+\mathrm{T}$ helper cells; it became clear that these cells play an important role in many immune-mediated and autoimmune diseases. ${ }^{15}$ The role of IL-17 in the pathogenesis of CSU was reported in previous studies in which IL-17 was found to be highly expressed in peripheral blood as well as in the skin of CSU patients. In this review, we will try to cover all published data on the emerging role of IL-17 in CSU and the possible benefit of targeting IL-17 in severe and refractory to standard therapy CSU patient.

\section{IL-I 7 in Peripheral Blood of CSU Patients}

In an early study, the level of circulating inflammatory cytokines, namely T-cell induced secretion and cytokine mRNA expression was assessed in patients suffering from chronic urticaria. Pro-inflammatory cytokines such as IL6 , TNF- $\alpha$ and IL-12 were found to be increased in chronic urticaria patients in association with increased IL-2 and IL-17 secretion following T-cell stimulation. ${ }^{16}$ The differentiation of Th17 cells is controlled by a transcription factor, ROR $\gamma \mathrm{T}$ but they also express variable levels of T-beta and Foxp3 transcription factors pointing to their dual functional role in different autoimmune diseases. The IL-17 family consists of IL-17A, IL-17B, IL-17C, IL-17D, IL-17E and IL-17F, of which IL-17A is the most studied. ${ }^{17}$ The involvement of IL-17-producing CD8+ $\mathrm{T}$ cells $(\mathrm{Tc} 17)$ in autoimmune diseases has been also reported in both humans and mice models. Cytokines such as IL-6, TGF- $\beta$ and interferon regulatory factor (IRF) 4 were reported to be important for Tc17 cells differentiation. Recent evidence ascertained a role for long-lived Tc17 memory cell populations, playing a functional role in mediating disease memory. ${ }^{18}$ Being 
implicated in autoimmune diseases, Th17 and Tc17 were analyzed for their possible role in CSU. Th17/Tc17 and Th1/Tc1 cells were evaluated in CSU patients who were ASST positive and compared with those who were ASST negative. The frequency of Tc17 and Tc1 was increased in ASST positive CSU patients as compared with ASST negative and healthy individuals. This is followed by increased production of IL-17A, TNF- $\alpha$ and many subsets of chemokines. These induce CCL20 which recruits CCR6-expressing cells such as Th17. All this strengthens the concept of cytotoxic T cells, mainly Tc1 and Tc17 subsets being involved in the pathogenesis of CSU particularly in the ASST positive group. ${ }^{19}$ Keeping all of the above in mind, serum levels of IL-17, TNF- $\alpha$, IL-23 and their association with urticaria activity score and ASST were examined in $75 \mathrm{CSU}$ patients and compared with 30 healthy subjects. Serum concentration of IL-17, IL-23 and TNF- $\alpha$ were significantly higher in CSU patients as compared with the control group. There was significant positive correlation between these cytokines and CSU disease activity as well as with ASST positivity. ${ }^{20}$ Interleukin-17 was demonstrated to be responsible (in part) for stimulating C-reactive protein (CRP) expression during immune-mediated responses. Therefore, the relationship between circulating concentrations of IL-17 and CRP in CSU was determined. IL-17 and CRP concentrations were significantly higher in CSU patients as compared with the healthy control group. CRP did not correlate significantly with IL-17 levels; however, the concentration of both was significantly higher in severe CSU patients than that in mild-moderate patients. Increased circulating IL-17 levels is therefore considered to be an independent marker of T-cell mediated inflammatory response in CSU, which is not related to an enhanced CRP level in severe CSU. ${ }^{21}$ Aspiring to further establish the role of IL-17 in the pathogenesis of CSU, plasma IL-17, IL-31, and IL-33 levels were quantified, mainly to examine their relationship with disease severity. The three cytokine concentrations were significantly higher in CSU patients when compared with those of healthy individuals. IL-17 levels were significantly higher in severe CSU patients than in moderate and mild $\mathrm{CSU}^{22}$ In a later study, Th1, Th2 and Th17 related cytokines were also found to be significantly higher in CSU patients than in healthy controls and in correlation with CSU disease severity. Granulocyte/macrophage colony-stimulating factor (GM-CSF) and IL-17 were significantly enhanced in ASST+ compared with that in ASST-CSU patients. ${ }^{23} \mathrm{CD} 4$
$+\mathrm{CD} 25+$ T-regulatory cells play important role in maintaining peripheral self-tolerance and preventing autoimmunity. Thus, the finding of a significant decrease in the percentage of circulating $\mathrm{CD} 4+\mathrm{CD} 25+\mathrm{FoxP} 3+$ $\mathrm{T}$ regulatory cells in patients with CSU was further proof suggesting that $\mathrm{T}$ cell auto-reactivity is a principal player in CSU autoimmunity. ${ }^{24}$ Once again, this highlights the functional role of $\mathrm{T}$ cells, specifically Th17 in the entire scenario of autoimmunity in CSU.

\section{IL- I 7 in the Skin}

IL-17A plays a central role in the pathogenesis of psoriasis. This was shown in several studies with the successful use of inhibiting antibodies [11]. It acts on nonhematopoietic cells, particularly epithelial cells, and plays an essential role in the immune response in neighboring organs. In the skin, IL-17A leads to increased proliferation and changed differentiation of keratinocytes, and induces antimicrobial peptides and IL-17A plays a central role in the pathogenesis of psoriasis.

This was shown in several studies with the successful use of inhibiting antibodies [11]. It acts on nonhematopoietic cells, particularly epithelial cells, and plays an essential role in the immune response in neighboring organs. In the skin, IL-17A leads to increased proliferation and changed differentiation of keratinocytes, and induces antimicrobial peptides and IL-17A was found to act mainly on non-hematopoietic cells, such as epithelial cells and keratinocytes, and play pivotal role in protective immunity at boundary tissues. In the skin, it was shown that IL-17A drives to the increased proliferation and aberrant differentiation of keratinocytes ${ }^{25}$ thus contributing to skin barrier disruption. This functional disruption is mainly due to downregulation of the expression of molecules involved in keratinocyte differentiation, such as filaggrin. ${ }^{26}$ On the other hand, it was shown that IL-17A participates in the inflammatory skin network by promoting the release of antimicrobial peptides and pro-inflammatory cytokines, ${ }^{27,28}$ which induce the activation of a neutrophil/Th17 cell-dependent immune response. These include IL-8, G-CSF and CCL20, which increase Th17 cell recruitment and the cytokines; IL-1 $\beta$ and IL-6. Furthermore, IL-17A directly contributes to skin remodeling by enhancing the secretion of metalloproteases. In psoriatic plaques, it was demonstrated that TNF $\alpha$ and IL-17A synergistically upregulate other proinflammatory cytokines in keratinocytes, such as IL36, which in turn was found to augment the function of Th17 cytokines. ${ }^{29}$ Thus, according to the above findings, it seems 
that IL-17 is an important player in skin immunity in general and in skin immune mediated diseases in particular. ${ }^{30}$ As was suggested in several studies, IL-17 promotes the expression and secretion of anti-microbial peptides mediated by the activation of NFkB, MAPKs and C/ EBPs. ${ }^{31}$ In atopic dermatitis (AD), it was found that at the acute and chronic phases of the inflammation, IL-17 and the expression of innate defense genes are reduced [(eg, lipocalin 2 (LCN2)]. This is presumably one of the main causes for the relatively high incidence of skin infections in $\mathrm{AD}$ patients. Therefore, it seems that the relative lack of expression of IL-17 in the skin of $\mathrm{AD}$ is a partial player in the pathogenesis of $\mathrm{AD}^{32}$ Drug eruption and Drug-induced hypersensitivity syndrome (DIHS) - are other diseases where Th17 cells are involved in the pathogenesis. The percentage of circulating Thl7 cells was increased in these groups of patients, especially in the erythema multiforme (EM) and Stevens-Johnson syndrome (SJS), as compared with the controls. It was also shown that the percentage of Th17 cells was decreased as the disease activity declined. ${ }^{33}$ These findings suggest that Th17 cells are involved in both Th1 and Th2 cutaneous disorder and fluctuate in parallel with the disease activities.

\section{IL-I 7 in the Skin of CSU Patients}

Mast cells and $\mathrm{T}$ cells are pivotal players in the pathogenesis of CSU. As such, efforts were made in order to explore mast cells $\backslash T$ cells interactions and the effects of several pro-inflammatory cytokines on mast cell's activation\degranulation during CSU. It was demonstrated in previous studies that there is a close physical proximity between mast cells and $\mathrm{T}$ cells in cell-mediated inflammatory diseases. Micro-particles released from activated T cells were shown to activate these mast cells. ${ }^{34}$ Some debate exists regarding the issue of IL-17 being produced by activated mast cells or whether mast cells actively uptake IL-17 into intracellular granules. ${ }^{35}$ Whether through up-take or production, IL-17 promotes mast cell's proliferation by triggering stem cell factor in keratinocytes. $^{36}$ In concurrence with the concept that CSU is a disease driven by both activated mast cells and activated CD4+ $\mathrm{T}$ cells, we recently generated a study aimed at exploring the involvement of IL-17 in the pathogenesis of CSU. In this study, we showed a high intense expression of IL-17A in the skin of CSU patients - both in lesional or non-lesional skin biopsies compared with normal skin. Furthermore, we demonstrated the intense infiltration of IL-17A expressing CD4+ T cells in the skin of
CSU patients; however, the primary importance of our finding was that for the first time, we presented evidence of increased IL-17A expression in skin mast cells in CSU. ${ }^{37}$ Looking at these biopsies it appears that IL-17A expressing CD4+ cells and mast cells are located in close proximity (Figure 1), suggesting that this finding is of mechanistic importance. Whether produced by CD4+ $\mathrm{T}$ cells and/or is truly produced by mast cells, IL-17A seems to play a major role in increasing the instability Idegranulation activity of skin mast cells in CSU. Additional studies are still needed in order to define these mechanistic issues (Figure 2). In addition, increased IL-17A expression could be due to an epiphenomenon. Our other finding in this study was that in both lesional or non-lesional skin biopsies from CSU patients there was a high level of expression of IL17A in CD4+T cells and mast cells but this was not the case in normal skin. This finding is in conformity with the hypothesis that in severe $\mathrm{CSU}$, the skin is infiltrated with immune cells. It is thought that following irritation by pro-inflammatory cytokines, including IL17, they induce a transient short-lasting mast cell's degranulation which may then resolve. Once CD4 + $\mathrm{T}$ cells and activated mast cells get closer to each other again, they induce new flares. This hypothesis might be

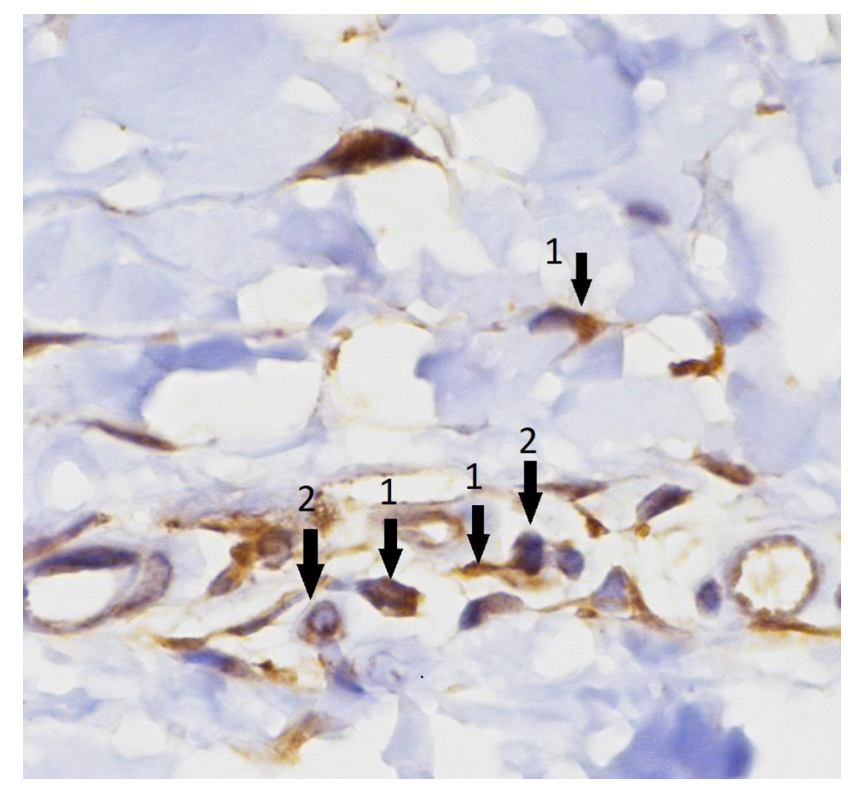

Figure I Increased expression of IL-I7A in both CD4+ T cells (arrows No.2) and mast cells (arrows No.I). In addition, the figure shows a closed proximity between T and mast cells.

Note: Reprinted with permission from Sabag DA, Matanes L, Bejar J, et al. Interleukin-17 is a potentialplayer and treatment target in severe chronic spontaneous urticaria.Clin Exp Allergy. 2020;50(7):799-804. Copyright 2020, John Wiley and Sons. ${ }^{37}$ 


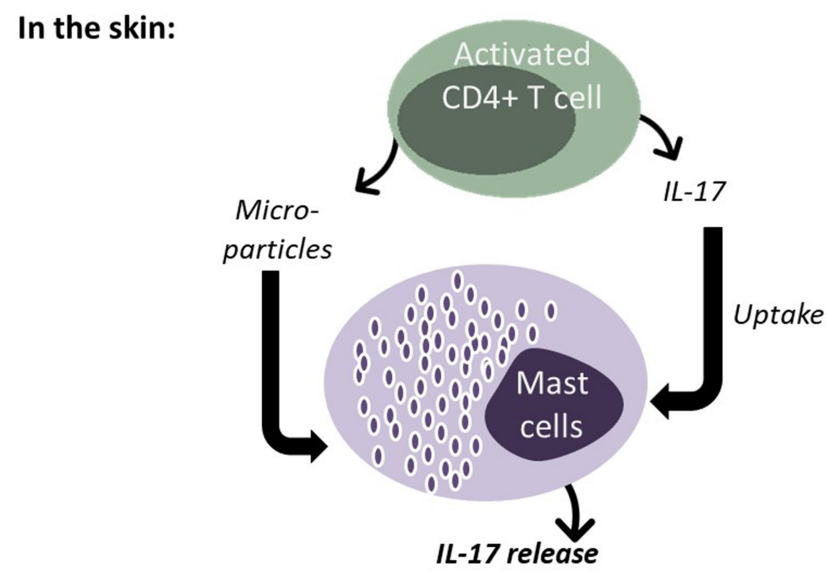

Figure 2 The possible mechanisms of the interaction between activated CD4 $\mathrm{T}$ cells and mast cells in the skin of CSU.

one of the explanations for the episodicltransient nature of the clinical attacks of hives in CSU. ${ }^{37}$

\section{New Targeted Therapies in Severe CSU}

The concept of targeting $\mathrm{T}$ cells, by applying cyclosporine A (CsA) in CSU had already been introduced in the early nineties, which assumed CD4+ T cells to be a major player in the pathogenesis of CSU. ${ }^{38}$ Later on, low-dose cyclosporine A (CsA) was also proven to be highly beneficial in severe CSU, including in some double-blind-placebo studies. ${ }^{39}$ Although associated with mild but transient side effects and in some patients, even intolerable, CsA induced complete remission in $40 \%$ of severe CSU patients and even considered to have curable abilities. ${ }^{40,41}$ The adverse effect profile (blood pressure and renal function) and (though un-proven), the fear of malignancy, prevented the extensive use of CsA in many countries. However, since it is considered a drug with a high evidence of efficacy in CSU, it is still recommended as an addon treatment by the EAACI/GA2LEN/EDE/WAO CSU guidelines, in patients with an inadequate response to highdose $\mathrm{H} 1$ anti-histamines. ${ }^{42}$ The extensive and widely published interest in defining type I and type II autoimmunity in the pathogenesis of CSU was followed by the swift FDA approval of the anti-IgE mAb (omalizumab) and its broad application in severe CSU. Omalizumab has been found to be considerably effective in Phase 2 and Phase 3 trials in CSU patients resistant to high-dose antihistamines and those requiring many short courses of steroids. Though considered an excellent option for severe CSU patients life-experience studies have shown that omalizumab has a beneficial response rate of $65 \%$, but only $40 \%$ of patients were completely free of urticaria attacks as long as omalizumab was continued. ${ }^{43}$ In one of the real-life experiences of $280 \mathrm{CSU}$ patients treated with omalizumab, more than half the patients achieved a complete response, but very few patients were able to stop taking omalizumab and remain free from symptoms. ${ }^{44}$ Moreover, $15-20 \%$ of CSU patients remain totally unresponsive to omalizumab and therefore they require other optional therapeutic strategies. ${ }^{45}$ Looking into the last decade, omalizumab has markedly improved the quality of life of CSU patients. However, there is still a group of patients who do not benefit from existing therapies and therefore require additional effective treatment. In this respect, novel investigational drugs are currently undergoing clinical trials aiming to assess their potential role in treating refractory CSU patients. Offlicence uses of currently available drugs include rituximab and TNF inhibitors. Ligelizumab (ant-IgE), Canakinumab (anti-IL-1), AZD1981 (a PGD2 receptor antagonist) and GSK 2,646,264 (a selective Syk inhibitor) are also currently in clinical trials for CSU treatment. Other potential drugs for the treatment of CSU are anti-IL4, anti-IL-5 and anti-IL13 all of which are examined in clinical trials. ${ }^{46,47}$

\section{The High Beneficial Effect of Targeting IL-I 7 in Patients with Severe CSU}

When severe and refractory CSU patients fail treatment with both omalizumab and CsA, and in order to spare the continuous usage of steroids, one should consider other off-label therapies. In this case, many other non-biological, non-antihistamine treatment options including methotrexate, colchicine, intravenous immunoglobulin (IVIG), plasmapheresis, dapsone and others have been widely assessed over many years, however, none of them gained sufficient evidence and have not been shown to have efficacy beyond the placebo effect and therefore non were included in CSU guidelines for classification and management. ${ }^{48}$ At this stage, it is more than clear that new drugs are required for CSU patients that are resistant to existing treatments. The reason for not focusing on targeting $\mathrm{T}$ cells as previously performed by CsA was due to the insufficient ongoing assessment of the role of T cells in CSU. Our recent study, in which IL-17 expression in both CD4+ T cells and mast cells was shown to be impressively increased in the skin of CSU patients, encouraged us to re-evaluate the strategy of targeting T cells, mainly IL-17 in severe and resistant CSU. We treated eight anti-histamine and omalizumab or CsA-resistant patients with anti-IL-17A 
(secukinumab); $150 \mathrm{mg}$ once a week for four consecutive weeks and then $150 \mathrm{mg}$ every 2 weeks afterward, which achieved a significant improvement of their symptoms. After 30 days, disease activity as assessed by UAS7 was improved by $55 \%$ from baseline. At this stage, omalizumab, CsA and steroids were discontinued completely. After 3 months, UAS7 was reduced by $82 \%$, mentioning only a few episodes of hives, only requiring antihistamines when needed. All patients were then maintained on secukinumab, remaining almost in full remission. Patients mentioned only local irritation at the site of injection. Remission was maintained as long as treatment was continued. When treatment was stopped (after 6-8 months) CSU was relapsed, suggesting that anti-IL-17 is required for longer periods. ${ }^{37}$ In fact, old friends such as the above-mentioned CsA was previously shown to inhibit IL-17 production by CD4+ T cells, possibly mediated by IL-15-activated NF-kappa B pathway in CD4+ T cells. ${ }^{49}$ In another earlier study, desloratadine citrate disodium (a non-sedative anti-histamine) reduced the level of serum IL-17 and chemokines in patients suffering from CSU, suggesting that targeting IL-17 is indeed very relevant. ${ }^{50}$ Further convincing evidences were published recently, thereby strengthening the concept that $\mathrm{T}$ cells are a proper candidate to be targeted in CSU. Drugs such as anti-IL5 (benralizumab and mepolizumab), anti-IL-4 (Dupilumab) and anti-IL1 (Canakinumab) are currently under development for the treatment of CSU. ${ }^{51,52}$

\section{Final Comments}

Autoimmunity in CSU is complex. It involves both humoral and cellular responses defined by the finding of autoantibodies and auto-reactive $T$ cells. The involvement of IL-17 in the pathogenesis of CSU and the beneficial response to anti-IL-17A treatment in severe CSU should encourage focusing on both the role of $\mathrm{T}$ cells and targeting $\mathrm{T}$ cells in CSU.

\section{Disclosure}

Prof. Dr. Elias Toubi and Prof. Dr. Zahava Vadasz report a patent Il-17 treatment in severe CSU patients pending. The authors report no other potential conflicts of interest for this work.

\section{References}

1. Leznoff A, Sussman GL. Syndrome of idiopathic chronic urticarial and angioedema with thyroid autoimmunity: a study of 90 patients. J Allergy Clin Immunol. 1989;84:66-71.
2. Ertas R, Hawro T, Altrichter S, et al. Antinuclear antibodies are common and linked to poor response to omalizumab treatment in patients with CSU. Allergy. 2020;75:468-470. doi:10.1111/all.14033

3. Rumbyrt JS, Katz A, Schocket AL. Resolution of chronic urticaria in patients with thyroid autoimmunity. $J$ Allergy Clin Immunol. 1995;96:901-905. doi:10.1016/S0091-6749(95)70226-1

4. Grattan CE, Wallington TB, Warin RP, Kennedy CT, Bradfield JW. A serological mediator in chronic idiopathic urticaria- a clinical, immunological and histological evaluation. $B r \quad J$ Dermatol. 1986;114:583-590. doi:10.1111/j.1365-2133.1986.tb04065.x

5. Abd El-Azim M, Abd El-Azim S. Chronic autoimmune urticaria: frequency and association with immunological markers. $J$ Investig Allergol Clin Immunol. 2011;21:546-550.

6. Hide M, Francis DM, Grattan CE, Hakimi J, Kochan JP, Greaves MW. Autoantibodies against the high-affinity $\operatorname{IgE}$ receptor as a cause of histamine release in chronic urticaria. $N$ Engl $J$ Med. 1993;328:1599-1604. doi:10.1056/NEJM199306033282204

7. Sanchez J, Sanchez A, Cardona R. Causal relationship between anti-TPO $\mathrm{IgE}$ and chronic urticarial by in-vitro and in-vivo tests. Allergy Asthma Immunol Res. 2019;11:29-42. doi:10.4168/aair.2019.11.1.29

8. Kolkhir P, Church MK, Weller K, Metz M, Schmetzer O, Maurer M. Autoimmune chronic spontaneous urticaria: what we know and what we do not know. J Allergy Clin Immunol. 2017;139:1772-1781. doi:10.1016/j.jaci.2016.08.050

9. Bracken SJ, Abraham S, MacLeod AS. Autoimmune theories of chronic spontaneous urticaria. Front Immunol. 2019;10:627. doi:10.3389/fimmu.2019.00627

10. Mekori YA, Giorno RC, Anderson P, Kohler PF. Lymphocyte subpopulations in the skin of patients with chronic urticaria. $J$ Allergy Clin Immunol. 1983;72:681-684. doi:10.1016/0091-6749(83)90629-2

11. Elias J, Boss E, Kaplan AP. Studies of the cellular infiltrate of chronic idiopathic urticaria: prominence of T-lymphocytes, monocytes, and mast cells. J Allergy Clin Immunol. 1986;78:914-918. doi:10.1016/ 0091-6749(86)90240-X

12. Toubi E, Adir-Shani A, Kessel A, Shmuel Z, Sabo E, Hacham H. Immune aberrations in $\mathrm{B}$ and $\mathrm{T}$ lymphocytes derived from chronic urticarial patients. J Clin Immunol. 2000;20:371-378. doi:10.1023/ A: 1006624331022

13. Toubi E, Blant A, Kessel A, Golan TD. Low-dose cyclosporine A in the treatment of severe chronic idiopathic urticaria. Allergy. 1997;52:312-316. doi:10.1111/j.1398-9995.1997.tb00996.x

14. Auyeung P, Mittag D, Hodgkin PD, Harrison L. Auto-reactive T cells in chronic spontaneous urticarial target the IgE Fc receptor I $\alpha$ subunit. J Allergy Clin Immunol. 2016;138:761-768. doi:10.1016/j. jaci.2016.04.036

15. Singh B, Schwartz JA, Sandrock C, Bellemore SM, Nikoopour E. Modulation of autoimmune diseases by interleukin (IL)-17 producing regulatory $\mathrm{T}$ helper (Th17) cells. Indian $J$ Med Res. 2013;138:591-594.

16. Dos Santos JC, Azor MH, Nojima VY, et al. Increased circulating pro-inflammatory cytokines and imbalanced regulatory T-cell cytokines production in chronic idiopathic urticaria. Int Immunopharmacol. 2008;8:1433-1440. doi:10.1016/j.intimp.2008.05.016

17. Taams LS, Steel KJA, Srenathan U, Burns LA, Kirkham BW. IL-17 the immune-pathogenesis of spondyloarthritis. Nat Rev Rheumatol. 2018;14:453-1466.

18. Liang Y, Pan HF, Ye DQ. Tc17 cells in immunity and systemic autoimmunity. Int Rev Immunol. 2015;34:318-331.

19. Lopes A, Machado D, Pedreiro S, et al. Different frequencies of Tc17/ Tc1 and Th17/Th1 cells in chronic spontaneous urticaria. Int Arch Allergy Immunol. 2013;161:155-162. doi:10.1159/000345401

20. Atwa MA, Emara AS, Youssef N, Bayoumy NM. Serum concentration of IL-17, IL-23 and TNF- $\alpha$ among patients with chronic spontaneous urticarial: association with disease activity and autologous serum skin test. J Eur Acad Dermatol Venerol. 2014;28:469-474. doi: $10.1111 / j \mathrm{dv} .12124$ 
21. Grazanka A, Damasiewicz-Bodzek A, Kasperska-Zajac A. The relationship between circulating concentrations of interleukin-17 and C-reactive protein in chronic spontaneous urticaria. Allergy Asthma Clin Immunol. 2017;13:25. doi:10.1186/s13223-017-0197-6

22. Lin W, Zhou Q, Liu C, Ying M, Xu S. Increased plasma IL-17, IL-31 and IL-33 levels in chronic spontaneous urticarial. Sci Rep. 2017;7:17797. doi:10.1038/s41598-017-18187-z

23. Chen Q, Zhong H, Chen WC, et al. Different expression patterns of plasma Th1, Th2, Th17 and Th22 related cytokines correlate with serum auto-reactivity and allergen sensitivity in chronic spontaneous urticaria. J Eur Acad Dermatol Venereol. 2018;32:441-448. doi:10.1111/jdv.14541

24. Arshi S, Babaie D, Nabavi M, et al. Circulating level of CD4+CD25 + Foxp3 $+\mathrm{T}$ cells in patients with chronic urticarial. Int J Dermatol. 2014;53:e561566. doi:10.1111/ijd.12630

25. Brembilla NC, Senra L, Boehncke W-H. The IL-17 family of cytokines in psoriasis: IL-17A and beyond. Front Immunol. 2018;9:1682. doi:10.3389/fimmu.2018.01682

26. Carrier Y, Ma HL, Ramon HE, et al. Inter-regulation of Th17 cytokines and the IL-36 cytokines in vitro and in vivo: implications in psoriasis pathogenesis. $J$ Invest Dermatol. 2011;131:2428-2437. doi:10.1038/jid.2011.234

27. Boutet M-A, Nerviani A, Pitzalis C. IL-36, IL-37, and IL-38 cytokines in skin and joint inflammation: a comprehensive review of their therapeutic potential. Int J Mol Sci. 2019;20:1257. doi:10.3390/ ijms20061257

28. Germàn B, Wei R, Hener P, et al. Disrupting the IL-36 and IL-23/IL-17 loop underlies the efficacy of calcipotriol and corticosteroid therapy for psoriasis. JCI Insight. 2019;4:e123390. doi:10.1172/jci.insight.123390

29. Buhl AL, Wenzel J. Interleukin-36 in infectious and inflammatory skin diseases. Front Immunol. 2019;10:1162. doi:10.3389/fimmu. 2019.01162

30. Mercurio L, FaillaID CM, Capriotti L, et al. Interleukin (IL)-17/IL-36 axis participates to the crosstalk between endothelial cells and keratinocytes during inflammatory skin responses). PLoS One. 2020;15 (4):e0222969. doi:10.1371/journal.pone.0222969

31. Gu C, Wu L, Li X. IL-17 family: cytokines, receptors and signaling. Cytokine. 2013;64:477-485.

32. Guttman-Yassky E, Lowes MA, Fuentes-Duculan J, et al. Low expression of the IL-23/Th17 pathway in atopic dermatitis compared to psoriasis. Immunol. 2008;181:7420-7427. doi:10.4049/ jimmunol.181.10.7420

33. Tokura Y, Mori T, Hino R. Psoriasis and other Th17-mediated skin diseases. J UOEH. 2010;32:317-328. doi:10.7888/juoeh.32.317

34. Shefler I, Salamon P, Reshef T, Mor A, Mekori YA. T cell-induced mast cell activation: a role for microparticles released from activated $\mathrm{T}$ cells. J Immunol. 2010;185:4206-4212. doi:10.4049/jimmunol.1000409

35. Noordenbos T, Blijdorp I, Chen S, et al. Human mast cells capture, store, and release bioactive, exogenous IL-17A. J Leukoc Biol. 2016;100(3):453-462. doi:10.1189/jlb.3HI1215-542R

36. Cho KA, Park M, Kim YH, Woo SY. Th17 cell-mediated immune responses promote mast cell proliferation by triggering stem cell factor in keratinocytes. Biochem Biophys Res Commun. 2017;487 (4):856-861. doi:10.1016/j.bbrc.2017.04.141
37. Sabag DA, Matanes L, Bejar J, et al. Interleukin-17 is a potential player and treatment target in severe chronic spontaneous urticaria. Clin Exp Allergy. 2020;50(7):799-804. doi:10.1111/cea.13616

38. Fradin MS, Ellis CN, Goldfarb MT, Voorhees JJ. Oral cyclosporine for severe chronic idiopathic urticarial and angioedema. J Am Acad Dermatol. 1991;1:1065-1067. doi:10.1016/0190-9622(91)70308-O

39. Grattan CE, Barlow RJ, O’Donnele BF, et al. Randomized double-blind study of cyclosporine in chronic idiopathic urticaria. Br J Dermatol. 2000;143:365-372. doi:10.1046/j.1365-2133. 2000.03664.x

40. Kessel A, Toubi E. Low-dose cyclosporine A is a good option for severe CU. J Allergy Clin Immunol. 2009;123:970. doi:10.1016/j. jaci.2009.01.065

41. Kessel A, Toubi E. Cyclosporine A in severe chronic urticarial: the option for long-term therapy. Allergy. 2010;65:478-482. doi:10.1111/ j.1398-9995.2010.02419.x

42. Zuberbier T, Aberer W, Asero R, et al. The EAACI/GA2LEN/EDE/ WAO guidelines for the definition, classification, diagnosis and management of urticarial. Allergy. 2018;73:1393-1414. doi:10.1111/ all.13397

43. Kaplan AP. Therapy of chronic urticaria: A simple, modern approach. Ann Allergy Asthma Immunol. 2014;112:419-425. doi:10.1016/j. anai.2014.02.014

44. Vadasz Z, Tal Y, Rotem M, et al. Omalizumab for severe chronic spontaneous urticaria: real-life experiences of 280 patients. J Allergy Clin Immunol Pract. 2017;5:1743-1745. doi:10.1016/j. jaip.2017.08.035

45. Maurer M, Gimenez-Arnau AM, Sussman G, et al. Ligelizumab for chronic spontaneous urticaria. N Eng J Med. 2019;381:1321-1332.

46. Kolkhir P, Altrichter S, Munoz M, Hawro T, Maurer M. New treatments for chronic urticaria. Ann Allergy Asthma Immunol. 2020;124:2-12. doi:10.1016/j.anai.2019.08.014

47. Kocaturk E, Maurer M, Metz M, Grattan C. Looking forward to new targeted treatments for chronic spontaneous urticaria. Clin Transl Allergy. 2017;7:1.

48. Kaplan AP. Diagnosis, pathogenesis, and treatment of chronic spontaneous urticaria. Allergy Asthma Proc. 2018;39:184-190. doi:10.2500/aap.2018.39.4121

49. Cho ML, Ju JH, Kim KW, et al. Cyclosporine A inhibits IL-15induced IL-17 production in CD4+ T cells via down-regulation of PI3K/Akt and NF-kappaB. Immunol Lett. 2007;108:88-96. doi:10.1016/j.imlet.2006.11.001

50. Wang J, Zhao Y, Yan X. Effects of desloratadine citrate disodium on serum immune function indices, inflammatory factors and chemokines in patients with chronic urticaria. J Coll Physicians Surg Pak. 2019;29:214-217.

51. Lee JK, Simpson RS. Dupilumab as a novel therapy for difficult to treat chronic spontaneous urticaria. J Allergy Clin Immunol Pract. 2019;7:1659-1661. doi:10.1016/j.jaip.2018.11.018

52. Kocaturk E, Zuberbier T. New biologics in the treatment of urticaria. Curr Opin Allergy Clin Immunol. 2018;18:425-431. doi:10.1097/ ACI.0000000000000466

\section{Publish your work in this journal}

ImmunoTargets and Therapy is an international, peer-reviewed open access journal focusing on the immunological basis of diseases, potential targets for immune based therapy and treatment protocols employed to improve patient management. Basic immunology and physiology of the immune system in health, and disease will be also covered. In addition, the journal will focus on the impact of management programs and new therapeutic agents and protocols on patient perspectives such as quality of life, adherence and satisfaction. The manuscript management system is completely online and includes a very quick and fair peer-review system, which is all easy to use. Visit http://www.dovepress.com/testimonials.php to read real quotes from published authors. 